\title{
Differential gene expression in Phaseolus vu/garis / locus NILs challenged with Bean common mosaic virus
}

Received: 9 September 2005 / Accepted: 20 February 2006 / Published online: 28 March 2006

(C) Springer-Verlag 2006

\begin{abstract}
The Phaseolus vulgaris I locus-Bean common mosaic virus (BCMV; Potyviridae) pathosystem is of critical importance to bean geneticists, breeders and pathologists because of the worldwide distribution of both the virus and germplasm containing this resistance gene. In order to learn more about the molecular responses characteristic of this resistance gene, a cDNA-AFLP screen was conducted on homozygous NILs of $P$. vulgaris variety 'Black Turtle Soup' (BT), containing either the $I$ locus allele for resistance $\left(\mathrm{BT}_{\mathrm{II}}\right)$ or susceptibility $\left(\mathrm{BT}_{\mathrm{ii}}\right)$ to $\mathrm{BCMV}$. Eight conditions were compared in a factorial analysis: $\mathrm{BT}_{\mathrm{II}}$ versus $\mathrm{BT}_{\mathrm{ii}}$; mock inoculated versus BCMV inoculated; 26 versus $34^{\circ} \mathrm{C}$. Transcripts induced in response to viral infection and that were further responsive to temperature, genotype or both were isolated and cloned. Sequence analysis of the resultant clones revealed several classes of putative genes, including transcription-related and signal transduction-related genes. Review of disease resistance literature suggests further avenues of research involving the candidates isolated in this screen.
\end{abstract}

\section{Introduction}

Disease resistance research is currently at the forefront in the field of plant biology and much effort has gone into the elucidation of what occurs between the recogni-

Communicated by F. J. Muehlbauer

M. Cadle-Davidson · M. M. Jahn

Department of Plant Breeding and Genetics,

Cornell University, Ithaca, NY 14853, USA

M. Cadle-Davidson ( $\square$ )

USDA-ARS, Grape Genetic Research Unit,

Geneva, NY 14456, USA

E-mail: mmc27@cornell.edu

Tel.: +1-315-7872462

Fax: +1-315-7872339 tion of a pathogen and the onset of defense. While resistance is the endpoint of known pathogen recognition signal transduction pathways, and genetic and biochemical evidence confirms roles for several genes in defense responses, the exact connections and intersections between the chemical, biochemical and physical reactions producing recognition-based or basal resistance are as yet unresolved (Rathjen and Moffett 2003; Belkhadir et al. 2004). Pathogenesis related (PR) genes are often expressed as a result of signal transduction (Maleck et al. 2000; Shah et al. 2001) and specific transcription factors have been identified whose interaction with PR gene promoters is required for their salicylic acid-dependent induction (Zhang et al. 1999, 2003; Zhou et al. 2000). Yet most PR genes have neither antimicrobial activity nor any direct effect on pathogen attack at all. What are the molecules that literally and immediately confer resistance? What stops the pathogen attack? Possible candidate molecules for the resistance endpoint are those, such as ubiquitin and protease inhibitors, that in some way modify or inhibit invading pathogen molecules (Heath et al. 1997; Jones and Takemoto 2004). However, these defense genes are hard to discover due to the likely scenario that the ultimate inhibition or death of the pathogen may be multifaceted and genetically redundant.

Efforts to dissect the resistance response employ both classical genetics and genomics-ranging from mutant screens to microarray studies. The use of transformation technology to confirm gene function in model species such as Arabidopsis and Nicotiana has resulted in large databases of phenotypic data. However, mutant screens can be confounded by epistasis and dominance, and microarrays can be too costly to examine all the relevant genotypes, environments, and pathogens and the microarrays themselves may not even include all the relevant genes. A great deal of data has been generated using these methods, but the complete picture still eludes us. Further, work in nonmodel systems can significantly limit a researcher's technology arsenal. An alternative approach - a differential dis- 
play-type method-can be sensitive enough to detect flux through a pathway while being cost-effective enough to screen multiple genotypes under multiple conditions. In particular, cDNA-AFLP can be performed under conditions of much higher stringency than other differential display methods, thus eliminating some potential for false positives (Bachem et al. 1996). Further, small variations at multiple points along a pathway as well as differences in timing or tissue-specificity of expression can be revealed (Bachem et al. 1996). As a result, differential screens often identify housekeeping or seemingly nonsensical genes; however, this is not entirely unreasonable especially in light of the Guard hypothesis (Dangl and Jones 2001; van der Biezen and Jones 1998). That is, if a cell is under attack by a pathogen it is feasible that normal metabolism or functioning may be perturbed and, in fact, this may well be what an R gene monitors (Dangl and Jones 2001; van der Biezen and Jones 1998).

In order to discover some of the transcriptional variation that occurs as either resistance or susceptibility develops, we evaluated a genetically simplified, yet agronomically relevant pathosystem: Bean common mosaic virus (BCMV) infection in I gene-containing Phaseolus vulgaris. BCMV is a member of the Potyviridae and, as such, encodes only eight proteins, whose functions have been characterized in BCMV and other closely related Potyviruses (Bos 1971; Urcuqui-Inchima et al. 2001). No single virulence factor or movement protein for this virus is known at this time, although several genes have been implicated as being involved with the latter (Urcuqui-Inchima et al. 2001). The $P$. vulgaris host genotypes used here are inbred, nearly isogenic lines (NIL) varying most significantly at the $I$ locus, so any variation detected in a differential expression study should be attributable to this locus. Resistance to BCMV conferred by the incompletely dominant $I$ allele is considered to be extreme at $26^{\circ} \mathrm{C}$ (Cadle-Davidson and Jahn 2005; Collmer et al. 2000; Drijfhout 1991). The "extreme" descriptor refers to the lack of any visible symptoms and the inability to recover virus from inoculated plants. However, upon inoculation at higher temperatures (above $30^{\circ} \mathrm{C}$ ), resistant plants develop necrotic lesions, systemic venal necrosis and, ultimately, apical death (Drijfhout 1991). Susceptible plants show chlorotic (sometimes necrotic) lesions and systemic mosaic at either temperature, although at high temperature symptoms develop faster and often lead to premature death (Drijfhout 1991).

In the present study a factorial cDNA-AFLP screen was conducted to compare expression between resistant and susceptible NILs of cv. 'Black Turtle Soup' (BT), $\mathrm{BT}_{\mathrm{II}}$ and $\mathrm{BT}_{\mathrm{ii}}$, at 26 and $34^{\circ} \mathrm{C}$. Bands of interest were cloned and sequenced and their sequences submitted for BLAST searches against the nonredundant and EST databases in Genbank. The results of these sequence analyses were compared with known genes involved in plant disease resistance responses.

\section{Materials and methods}

\section{Germplasm}

Near isogenic lines of $P$. vulgaris variety BT homozygous for either the dominant $\left(\mathrm{BT}_{\mathrm{II}}\right)$ or recessive allele $\left(\mathrm{BT}_{\mathrm{ii}}\right)$ were used in these experiments (Cadle-Davidson 2005; Provvidenti 1983). The NILs were originally resistant and susceptible selections from a seed lot of BT (Provvidenti 1983). Since this selection the lines have been backcrossed for five generations in order to homogenize the genetic background (Cadle-Davidson 2005). In theory, this level of backcrossing retains approximately $1.5 \%$ of the donor genome, however the actual remnant in these lines is likely much less due to the fact that the initial genotypes were already very closely related. All experimental plant material was maintained in a growth chamber at $26^{\circ} \mathrm{C}$ days $/ 22^{\circ} \mathrm{C}$ nights or $34^{\circ} \mathrm{C}$ days $/ 31^{\circ} \mathrm{C}$ nights with a $16 \mathrm{~h}$ photoperiod.

Viral isolate maintenance and inoculation

Bean common mosaic virus NY15 68/95 was obtained from R. Provvidenti (Geneva, NY, USA) and maintained on the $P$. vulgaris variety 'California Light Red Kidney' (CLRK), a mosaic-producing host. Rub inoculations were performed using sap extracted from fresh, highly symptomatic CLRK leaves by grinding in a chilled mortar with carborundum (400 mesh) and $0.05 \mathrm{M}$ $\mathrm{KH}_{2} \mathrm{PO}_{4}$.

\section{RNA isolation and cDNA-AFLP}

Samples for RNA extraction and cDNA-AFLP analysis were collected at 4 days post inoculation, immediately frozen in liquid nitrogen and stored at $-80^{\circ} \mathrm{C}$. This material consisted of: $\mathrm{BT}_{\mathrm{II}}$ mock-inoculated (buffer only), $26^{\circ} \mathrm{C} ; \mathrm{BT}_{\mathrm{II}} \mathrm{BCMV}$-inoculated, $26^{\circ} \mathrm{C} ; \mathrm{BT}_{\mathrm{II}}$ mockinoculated, $34^{\circ} \mathrm{C} ; \mathrm{BT}_{\text {II }} \mathrm{BCMV}$-inoculated, $34^{\circ} \mathrm{C} ; \mathrm{BT}_{\mathrm{ii}}$ mock-inoculated (buffer only), $26^{\circ} \mathrm{C} ; \mathrm{BT}_{\mathrm{ii}} \mathrm{BCMV}$-inoculated, $26^{\circ} \mathrm{C} ; \mathrm{BT}_{\mathrm{ii}}$ mock-inoculated, $34^{\circ} \mathrm{C} ; \mathrm{BT}_{\mathrm{ii}} \mathrm{BCMV}$ inoculated, $34^{\circ} \mathrm{C}$. A single primary (inoculated or mockinoculated) leaf from each sample was used as starting material for the RNA preparation. RNA isolation and cDNA-AFLP procedures and primer sequences were as in Bachem et al. (1996). All 256 primer combinations described by Bachem et al. (1996) were used. RNA extraction buffer volumes were scaled down to one fourth of the original protocol to account for the reduced amount of tissue used here.

\section{Clone isolation and validation}

Bands that reflected gene induction relevant to the pathosystem being studied were isolated and cloned. Selection criteria consisted of: (1) Responsiveness to viral infection; (2) Responsiveness to heat; (3) Responsiveness to genotype - specifically the presence of the $I$ 
allele; and (4) Combinations of 1 and 3. Gel slices corresponding to the bands of interest were boiled and used as template for PCR using the primer sets from the original amplification. Following this PCR and confirmation of product by agarose gel electrophoresis, the PCR product was cloned into EcoRV-digested pBlueScript KS- to which a $\mathrm{T}$ overhang had been added by incubation at $70^{\circ} \mathrm{C}$ with $1 \mathrm{U}$ Taq DNA polymerase and $50 \mathrm{mM}$ dTTP. All clones were sequenced using the M13 forward primers by the Bioresource Center, Cornell University, Ithaca, NY, USA. Validation of clones was performed by northern analysis using a panel of RNAs extracted from a second experiment using the same genotypes, inoculation, and environmental conditions as were used for the original screen.

\section{Sequence analysis}

All sequence analysis was performed using the Lasergene suite of sequence analysis programs (DNAstar) and Sequencher (Gene Codes Corporation). Redundant clones were eliminated at this point. Following annotation of sequence data, all clones were submitted to NCBI BLAST comparisons in an attempt to determine their identities. The procedure used for identifying each clone was to first BLASTn each sequence in the nonredundant (nr) database. If no hits were found in this database that met the Expect $\left(E \leq 10^{-5}\right)$ criterion, the sequence was then submitted to BLASTn against the EST database. The original sequence was also used to perform a translated BLAST (BLASTx) on the protein database. If the original sequence returned a significant match only in the EST database, the resultant EST was used to BLAST the nr and protein databases.

\section{Results}

Several banding patterns were present in the materials tested here including uniform expression for the majority of bands detected. This was expected due to the fact that the starting plant materials are NILs that differ primarily at the $I$ locus. Seven different banding patterns (Fig. 1) were considered interesting in the context of these experiments and only bands that fit into these categories (labeled a-g) were extracted and cloned. With the exception of (e), all bands cloned were virus-dependent. The relevant banding patterns were: (a) temperature-dependent size variant; (b) $\mathrm{BT}_{\mathrm{II}}$ specific, temperature-independent; (c) genotype-dependent differential abundance; (d) heat responsive, virus-dependent; (e) heat responsive, virus-independent; (f) high temperature induction; and $(\mathrm{g}), \mathrm{BT}_{\mathrm{II}}$-specific, high temperature only. Pattern (a) was selected without knowledge of whether the bands were derived from the same or different genes and both bands were isolated. In total, 59 bands were identified as being meaningful and were extracted from the gels.
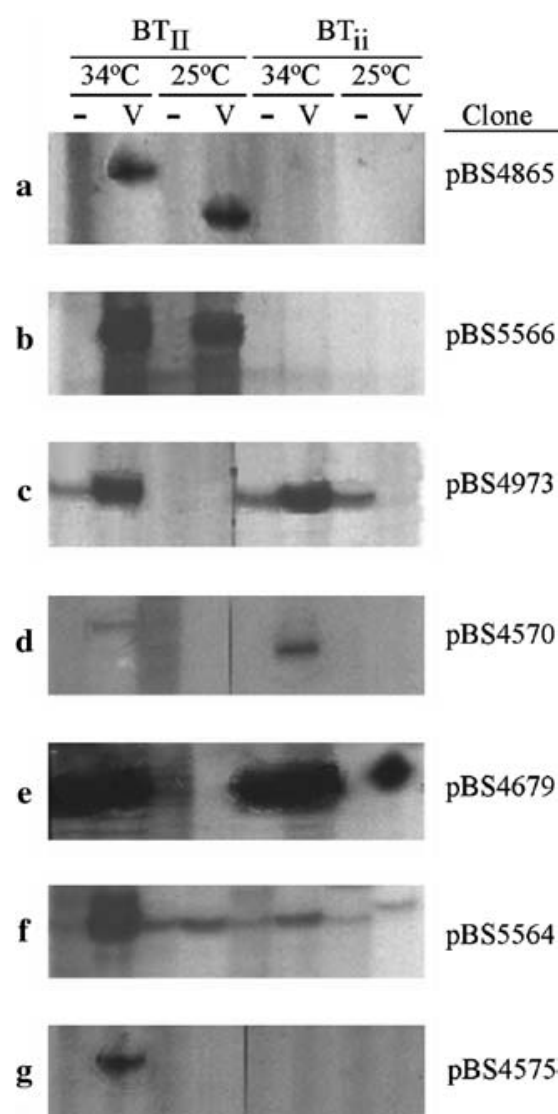

Fig. 1 Examples of expression patterns from cDNA-AFLP gels when $\mathrm{BT}_{\mathrm{II}}$ and $\mathrm{BT}_{\mathrm{ii}}$ were compared at 25 and $34^{\circ} \mathrm{C}$. RNA for this analysis was collected 4 days post inoculation or mock inoculation. Letters a-g represent classes of banding patterns and are represented by images of single clones each. $V$ BCMV-inoculated sample, - mock inoculated sample. a Temperature-dependent size variation, $\mathbf{b} \mathrm{BT}_{\mathrm{II}}$ specific, temperature-independent, c genotype-dependent differential abundance, $\mathbf{d}$ heat responsive, virus-dependent, e heat responsive, virus-independent, $\mathbf{f}$ high temperature induction, $\mathbf{g} \mathrm{BT}_{\mathrm{II}^{-}}$ specific, high temperature only

Sequence analysis revealed that most of the clones were redundant and the original number of cloned bands was reduced to 19 unique clones (Table 1) with 17 of these being confirmed by northern analysis. All confirmed sequences were submitted to the Genbank database and their accession numbers are included in Table 1. Banding pattern (a) resulted in either one or two unique sequences and only the former were retained in this study. A number of reasons for the presence of two different length fragments derived from the same sequence may be cited, including alternative splicing, expression from different gene family members or alternative starts/stops. All of these are reasonable possibilities based on the fact that transcription and transcription factors are frequently influenced by environmental and biotic factors (FerrierCana et al. 2005; Kaldis et al. 2003). Table 1 shows the results of the sequence analyses conducted on the cDNAAFLP clones. The sequences identified by the cDNAAFLP experiments presented here are comprised of genes that can be categorized as transcription-related, signal 
Table 1 cDNA-AFLP clones showing differential expression between P. vulgaris NILs, $\mathrm{BT}_{\mathrm{II}}$ and $\mathrm{BT}_{\mathrm{ii}}$, and at 25 versus $34^{\circ} \mathrm{C}$

\begin{tabular}{|c|c|c|c|c|}
\hline \multirow[t]{2}{*}{ Clone (Genbank accession) } & \multirow{2}{*}{$\begin{array}{l}\text { Banding } \\
\text { pattern }\end{array}$} & \multicolumn{3}{|l|}{ BLAST results } \\
\hline & & GenBank accession & $E$ value & Description \\
\hline $\begin{array}{l}\text { Signal transduction } \\
\text { pBS4773 (DW177223) }\end{array}$ & g & AY463016.1 & $2.00 \mathrm{E}-11$ & $\begin{array}{l}\text { Musa acuminata putative beta } \\
\text { family G-protein }\end{array}$ \\
\hline pBS5077 (DW177230) & g & BAC05575.1 & $4.00 \mathrm{E}-74$ & $\begin{array}{l}\text { Oryza sativa protein phosphatase } \\
\text { 2C-like protein }\end{array}$ \\
\hline $\begin{array}{l}\text { Defense } \\
\text { pBS4575 (DW177218) }\end{array}$ & $\mathrm{g}$ & AY248742 & $4.00 \mathrm{E}-28$ & $\begin{array}{l}\text { L. esculentum omega- } 3 \text { fatty } \\
\text { acid desaturase gene }\end{array}$ \\
\hline pBS4571 (DW177217) & $\mathrm{c}$ & AJ320268 & $3.00 \mathrm{E}-26$ & P. paniceum malate deshydrogenase \\
\hline pBS4665 (DW177219) & a & X75082 & $6.00 \mathrm{E}-38$ & $\begin{array}{l}\text { S. tuberosum mRNA for mitochondrial } \\
\text { citrate-synthase }\end{array}$ \\
\hline pBS4679 (DW177220) & $\mathrm{e}$ & X14060 & $8.00 \mathrm{E}-41$ & $\begin{array}{l}\text { L. esculentum nia gene for } \\
\text { lnitrate reductase (EC 1.6.6.1) }\end{array}$ \\
\hline pBS4764 (DW177221) & $\mathrm{e}$ & X05984.1 & $9.00 \mathrm{E}-08$ & $\begin{array}{l}\text { Tomato rbcS3A gene for ribulose } \\
\text { 1,5-bisphosphate carboxylase/oxygenase }\end{array}$ \\
\hline pBS4973 (DW177229) & $\mathrm{c}$ & K00507 & $6.00 \mathrm{E}-50$ & $\begin{array}{l}\text { Tobacco chloroplast atpase gene } \\
\text { (b and e subunits) }\end{array}$ \\
\hline $\begin{array}{l}\text { Unknown } \\
\text { pBS4777 (DW177224) }\end{array}$ & $\mathrm{g}$ & AAM63708.1 & $1.00 \mathrm{E}-71$ & $\begin{array}{l}\text { O. sativa putative zinc-finger, } \\
\text { heat shock protein }\end{array}$ \\
\hline pBS4865 (DW177225) & $\mathrm{a}$ & AF233745 & $1.00 \mathrm{E}-06$ & L. esculentum chaperonin 21 precursor \\
\hline
\end{tabular}

a Temperature-dependent size polymorphism

${ }^{\mathrm{b}} \mathrm{BT}_{\mathrm{II}}$ specific

${ }^{c}$ Genotype-dependent differential abundance

d High temperature size/abundance polymorphism

${ }^{\mathrm{e}}$ Heat responsive

${ }^{\mathrm{f}}$ High temperature increased abundance

${ }^{\mathrm{g}} \mathrm{BT}_{\mathrm{II}}$ specific, high temperature only

transduction-related, defense-related, "housekeeping" genes and others that do not give insight into their relevance to this study.

\section{Discussion}

In the present study isolines for the Phaseolus virus resistance locus, $I$, were differentially screened using cDNAAFLP. The rigor of the experimental design aided the discovery of candidate genes induced by the interaction of BCMV and the $I$ locus due to the fact that genotype, environment and infection state were controlled for. Specifically, resistant and susceptible NILs were tested at both normal and elevated temperatures and in both the inoculated and mock-inoculated condition. The factorial design eliminates selection of many false-positive banding patterns and allows for the identification of bands that are present only in the presence of viral infection as well as in association with resistance. This combination of genetics and differential expression screen is very powerful: because there are very few genetic differences between the BT NILS, any differences in gene expression are likely due to the influence of the $I$ locus. Further, the conditions tested here included virus-infected samples at "permissive" $\left(34^{\circ} \mathrm{C}\right)$ and "restrictive" $\left(26^{\circ} \mathrm{C}\right)$ temperatures. It is well known that viral infection leads to alteration of gene expression and that this, in part, is due to viral recruitment of the cellular transcription machinery for its own use (Hull 2002). Therefore, the differential expression seen in this study should be viewed as having 
two sources: (1) defensive regulation controlled by host cells in order to combat infection and heat shock and (2) viral manipulation of cellular transcription for the purpose of replication and movement.

In a similar study, Vallejos et al. (2000) compared bulked samples homozygous for either $I$ or $i$ from a population of recombinant inbred lines (76 lines in the complete population). This study did much to account for the genetic background and identified RNA-level differences between resistance and susceptibility. A further result of their research was the discovery sequences genetically linked the $I$ locus that may prove beneficial in the positional cloning of this resistance locus (Vallejos et al. 2000). However, they did not address the complete interaction of the $I$ locus with pathogen or environment either by inoculation with BCMV or by exposure to the permissive and restrictive temperatures (Vallejos et al. 2000). Further, the clones isolated in the Vallejos et al. (2000) study were not sequenced and as a result, no additional comparisons between their study and the present one may be made.

Clones pBS4773, 4866 and 5077 show significant sequence similarity to components of an ethylene-responsive G-protein signaling system $(4773,4866)$ and an ABA sensitive protein phosphatase 2C (5077) (Table 1) (Roehl et al. 1995; Zegzouti et al. 1999). It is reassuring that we identified three potential components of the same signal transduction pathway in our screen and that they share the same banding pattern. At this time, stress responsive ABA signaling is the only pathway in plants known to function via G-protein signaling (Leung et al. 1997; Jones 2002). The possibility that a stress-related signaling pathway is induced in a resistant-genotype-dependent manner in response to viral infection is inviting in that it suggests that general, not specialized, pathways are used by a plant host in order to combat infection and is consistent with the growing evidence for crosstalk between signaling pathways (Kachroo et al. 2003).

By reviewing the molecular plant pathology literature, some of these genes' functions can be speculated upon; however, this is only useful in hypothesis generation. In this regard, the clones generated in these experiments are candidates for further hypothesis-driven assays into the molecular interactions of the $I$ locus-BCMV pathosystem and, perhaps, virus resistance, in general.

Acknowledgements We thank L. Cadle-Davidson, G. Rairdan, S. Restrepo, P. Griffiths, S. McCouch, and T. Zitter for critical review of this manuscript and insightful discussions during the course of this work and G. Moriarty for technical assistance. M.M. CadleDavidson was supported in part by the Interdisciplinary Research Training Group in Molecular Mechanisms of Plant Processes (NSF Grant DBI-9420687).

\section{References}

Bachem CWB, vanderHoeven RS, deBruijn SM, Vreugdenhil D, Zabeau M, Visser RGF (1996) Visualization of differential gene expression using a novel method of RNA fingerprinting based on AFLP: analysis of gene expression during potato tuber development. Plant J 9:745-753
Belkhadir Y, Subramaniam R, Dangl JL (2004) Plant disease resistance protein signaling: NBS-LRR proteins and their partners. Curr Opin Plant Biol 7:391-399

van der Biezen EA, Jones JDG (1998) Plant disease-resistance proteins and the gene-for-gene concept. Trends Biochem Sci 23:454 456

Bos L (1971) Bean common mosaic virus. Descriptions of plant viruses, vol 73

Cadle-Davidson MM (2005) Mechanism of resistance to Bean common mosaic virus conferred by the I locus in Phaseolus vulgaris $L$. Dissertation. Plant breeding and genetics. Cornell University, Ithaca, $\mathrm{p} 98$

Cadle-Davidson MM, Jahn MM (2005) Resistance conferred against Bean common mosaic virus by the incompletely dominant I locus of Phaseolus vulgaris is active at the single cell level. Arch Virol 150:2601-2608

Collmer CW, Marston MF, Taylor JC, Jahn M (2000) The $I$ gene of bean: a dosage-dependent allele conferring extreme resistance, hypersensitive resistance, or spreading vascular necrosis in response to the potyvirus Bean common mosaic virus. Mol Plant Microbe Interact 13:1266-1270

Dangl JL, Jones JDG (2001) Plant pathogens and integrated defence responses to infection. Nature 411:826-833

Drijfhout E (1991) Bean common mosaic. Compendium of bean diseases. APS Press, Saint paul, pp 37-39

Ferrier-Cana E, Macadre C, Sevignac M, David P, Langin T, Geffroy V (2005) Distinct post-transcriptional modifications result into seven alternative transcripts of the CC-NBS-LRR gene JAltr of Phaseolus vulgaris. Theor Appl Genet 110:895905

Heath RL, McDonald G, Christeller JT, Lee M, Bateman K, West J, vanHeeswijck R, Anderson MA (1997) Proteinase inhibitors from Nicotiana alata enhance plant resistance to insect pests. J Insect Physiol 43:833-842

Hull R (2002) Matthews' plant virology. Academic, San Diego

Jones AL (2002) G-protein-coupled signaling in Arabidopsis. Curr Opin Plant Biol 5:402-407

Jones DA, Takemoto D (2004) Plant innate immunity — direct and indirect recognition of general and specific pathogen-associated molecules. Curr Opin Immunol 16:48-62

Kachroo A, Lapchyk L, Fukushige H, Hildebrand D, Klessig DF, Kachroo P (2003) Plastidial fatty acid signaling modulates salicylic acid- and jasmonic acid-mediated defense pathways in the Arabidopsis ssi2 mutant. Plant Cell 15:2952-2965

Kaldis AD, Kousidis P, Kesanopoulos K, Prombona A (2003) Light and circadian regulation in the expression of $L H Y$ and $L h c b$ genes in Phaseolus vulgaris. Plant Mol Biol 52:981-997

Leung J, Merlot S, Giraudat J (1997) The Arabidopsis ABSCISIC $A C I D-I N S E N S I T I V E 2$ ( $A B I 2)$ and $A B I 1$ genes encode homologous protein phosphatases $2 \mathrm{C}$ involved in abscisic acid signal transduction. Plant Cell 9:759-771

Maleck K, Levine A, Eulgem T, Morgan A, Schmid J, Lawton KA, Dangl JL, Dietrich RA (2000) The transcriptome of Arabidopsis thaliana during systemic acquired resistance. Nat Genet 26:403410

Provvidenti R (1983) Two useful selections of the bean cultivar Black Turtle Soup for viral identification. Bean Improv Coop Annu Rep 26:73-75

Rathjen JP, Moffett P (2003) Early signal transduction events in specific plant disease resistance. Curr Opin Plant Biol 6:300-306

Roehl T, Caliebe A, Seedorf M, Soll J (1995) Characterization of four cDNAs encoding small GTP-binding proteins from pea. Plant Physiol 109:1125

Shah J, Kachroo P, Nandi A, Klessig DF (2001) A recessive mutation in the Arabidopsis SSI2 gene confers SA- and NPRI-independent expression of PR genes and resistance against bacterial and oomycete pathogens. Plant J 25:563-574

Urcuqui-Inchima S, Haenni A-L, Bernardi F (2001) Potyvirus proteins: a wealth of functions. Virus Res 74:157-175

Vallejos CE, Malandro JJ, Sheehy K, Zimmermann MJ (2000) Detection and cloning of expressed sequences linked to a target gene. Theor Appl Genet 101:1109-1113 
Zegzouti H, Jones B, Frasse P, Marty C, Maitre B, Latche A, Pech J, Bouzayen M (1999) Ethylene-regulated gene expression in tomato fruit: characterization of novel ethylene-responsive and ripening-related genes isolated by differential display. Plant $\mathbf{J}$ 18:589600

Zhang YL, Fan W, Kinkema M, Li X, Dong X (1999) Interaction of $N P R 1$ with basic leucine zipper protein transcription factors that bind sequences required for salicylic acid induction of the $P R-1$ gene. Proc Natl Acad Sci USA 96:6523-6528
Zhang YL, Tessaro MJ, Lassner M, Li X (2003) Knockout analysis of Arabidopsis transcription factors $T G A 2, T G A 5$, and $T G A 6$ reveals their redundant and essential roles in systemic acquired resistance. Plant Cell 15:2647-2653

Zhou JM, Trifa Y, Silva H, Ponteir D, Lam E, Shah J, Klessig DF (2000) NPRI differentially interacts with members of the TGA/ OBF family of transcription factors that bind an element of the $P R-1$ gene required for induction by salicylic acid. Mol Plant Microbe Interact 13:191-200 